\title{
PENGARUH PENAMBAHAN SERAT IJUK PADA PAVING BLOCK BERBAHAN PLASTIK HDPE
}

\author{
Denny Meisandy Hutauruk ${ }^{1}$, Muhammad Irwansyah², Akbar Alfa ${ }^{3}$ \\ ${ }^{1}$ Jurusan Pendidikan Teknik Bangunan, Fakultas Teknik, Universitas Negeri Medan \\ ${ }^{2}$ Prodi Teknik Sipil, Fakultas Teknik, Universitas Asahan \\ ${ }^{3}$ Prodi Teknik Sipil Fakultas teknik dan Ilmu Komputer, Universtias Islam Indragiri \\ Email: denny_ft@unimed.ac.id (korespondensi)
}

\begin{abstract}
The waste problem continues to be a complex issue. On the one hand, the use of plastic still cannot be abandoned by humans, but on the other hand the waste produced is very difficult to decompose. In Indonesia, in 2015 the amount of waste reached 64 million tons / year. Palm fiber is one of the materials that can be used as composite fiber. In this study, a research will be conducted on the manufacture of paving blocks made from HDPE plastic combined with variations of $0 \%, 1 \%, 2 \%$ and $3 \%$ palm fiber. Plastic waste is melted and put into a mold and then combined with palm fiber. From the test results, the highest compressive strength ( $2 \%$ fiber variation) was $45.91 \mathrm{~kg} / \mathrm{cm}^{2}$ and the average compressive strength was $45.28 \mathrm{~kg} / \mathrm{cm}^{2}$. This compressive strength is under the minimum compressive strength standard of SNI.
\end{abstract}

Keywords: Paving block, HDPE plastic, palm fiber, compressive strength

\begin{abstract}
Abstrak
Permasalahan sampah masih terus menjadi isu kompleks. Di satu sisi, penggunaan plastik masih belum bisa ditinggalkan manusia, namun di sisi lain sampah yang dihasilkan sangat sulit terurai. Di indonesia, pada tahun 2015 tercatat banyaknya sampah mencapai 64 juta ton/tahun. Ijuk merupakan salah satu material yang dapat digunakan sebagai serat komposit. Pda penelitian ini akan dilakukan penelitian mengenai pembuatan paving block berbahan dasar plastik HDPE yang dikombinasikan dengan variasi serat ijuk 0\%, 1\%, $2 \%$ dan 3\%. Limbah plastik dilelehkan dan dimasukkan ke dalam cetakan lalu dipadukan dengan serat ijuk. Dari hasil pengujian, didapatkan kuat tekan tertinggi (variasi serat 2\%) sebesar $45,91 \mathrm{~kg} / \mathrm{cm}^{2}$ dan kuat tekan rata-ratanya sebesar $45,28 \mathrm{~kg} / \mathrm{cm}^{2}$. Kuat tekan ini berada di bawah standar kuat tekan minimal dari SNI.
\end{abstract}

Kata kunci: Paving block, plastik HDPE, serat ijuk, kuat tekan

\section{Pendahuluan}

Kuantitas sampah plastik terus menerus meningkat di Indonesia, terutama daerah perkotaan dalam 10 tahun terakhir. Tren timbulan sampah plastik mulai dari $11 \%$ di tahun 2005 meningkat menjadi $15 \%$ di tahun 2015.

Masalah sampah plastik ini cukup serius, mengingat sampah plastik merupakan salah satu jenis yang paling sulit terurai. Waktu yang diperlukan untuk mengurai sampah plastik dapat mencapai 400 tahun. Untuk itu, perlu adanya upaya untuk mengurangi limbah plastik, seperti mengolah kembali menjadi produk tepat guna.
Ijuk merupaka serat yang dihasilkan oleh tumbuhan aren yang dapat tumbuh di seluruh daratan Indonesia, terutama pada ketinggian 400 hingga $1000 \mathrm{mdpl}$. Seratserat ijuk yang dihasilkan oleh pohon aren dapat dipanen setelah berumur lima tahun. Beberapa sifat fisik dari ijuk diantaranya: berwarna hitam, bersifat kaku, ulet dan tahan air. Selama ini penggunaan ijuk masih belum banyak, yaitu masih sebatas keperluan rumah tangga. Beberapa pengguaan tersebut yaitu sebagai bahan pembuat sapu, keset dan tali. Padahal, produksi ijuk secara nasional dapat mencapai 165.000 per tahunnya. 
Secara umum penelitian ini adalah untuk mengetahui pengaruh penambahan serat ijuk terhadap kuat tekan paving block berbahan dasar limbah plastik HDPE (HighDensity Polyethylene). Penelitian ini juga merupakan upaya untuk bisa mengurangi jumlah limbah sampah plastik.

\section{TINJAUAN PUSTAKA}

\subsection{Plastik}

Terdapat beberapa macam plastik, beberapa diantaranya yaitu:

1. Polyvinyl Chloride (PVC)

2. Ploypropylene (PP)

3. Polystyrene (PS)

4. Polyethylene Terephthalate (PETE)

5. Low-Density Polyethylene (LDPE)

6. High-Density Polyethylene (HDPE)

Plastik HDPE merupakan jenis plastik yang memiliki simbol daur ulang dan angka 2 ditengahnya. Biasanya plastik jenis ini digunakan sebagai kemasan makanan atau minuman panas, sebagai botol, atau sebagai plastik belanjaan. Adapun warna dari plastik jenis ini ialah lebih buram jika dibandingkan dengan jenis LDPE.

Hutauruk (2021) membuat paving block berbahan dasar plimbah plastik HDPE dengan serat bendrat. Dari hasil penelitian, didapatkan kuat tekan mencapai $110,7 \mathrm{~kg} / \mathrm{cm} 2$. Kuat tekan tersebut masuk ke dalam kategori paving block kelas D.

\subsection{Serat Ijuk}

Serat ijuk merupakan salah satu serat alami yang bisa didapatkan dari alam. Beberapa jenis serat alami yang lain yaitu serat sabut kelapa, ramie dan yang lainnya (Adibroto, 2014).

Dalam penelitian beton, ada berbagai macam serat yang digunakan. Adibroto, Fauna (2014) meneliti pengaruh penambahan berbagai jenis serat pada kuat tekan paving block, yaitu serat plastik, serat kawat bendrat dan serat ijuk.

Perdana, dkk (2015) meneliti pengaruh serat ijuk pada campuran beton. Adapun hasil penelitian yaitu adanya peningkatan kuat tarik.

Samlawi (2017) meneliti penggunaan serat ijuk sebagai bahan baku cover body sepeda motor, dimana kesimpulannya yaitu material komposit serat ijuk dapat dijadikan bahan alternatif. Pengujian yang dilakukan berupa uji tarik dan uji impact.

\subsection{Paving Block}

Paving block merupakan salah satu jenis perkerasan. Secara umum, paving block terbuat dari campuran semen hidrolis, agregat dan air. Paving block memiliki warna seperti beton pada umumnya atau diberi warna untuk menambah estetika.

Di indonesia, paving block baru dikenal pada tahun 1977. Aplikasi paving block pada saat itu yaitu pada pembuatan trotoal di Jakarta, tepatnya di jalan Thamrin dan Terminal Bis Pulo Gadung.

Sebagai material yang digunakan sebagai perkerasan, paving block memiliki beberapa keunggulan, seperti:

a. Dapat diproduksi secara massal

b. Lebih mudah dalam pekerjaan, yaitu dengan cara penghamparan dan bisa langsung digunakan.

c. Pada saat pemasangan tidak menimbulkan kebisingan dan gangguan debu

d. Biaya perawatan yang rendah Syarat mutu paving block ialah harus memenuhi kriteria berikut:

a. Permukaan paving block harus rata, tidak retak, bagian sudut dan rusuknya tidak mudah digerus dengan kekuatan jari tangan

b. Paving block harus memiliki sifat fisika seperti pada Tabel 1.

Tabel 1. Kuat Fisik Paving Block

\begin{tabular}{|c|c|c|c|c|c|}
\hline \multirow[t]{2}{*}{ Mutu } & \multicolumn{2}{|c|}{ Kuat Tekan (Mpa) } & \multicolumn{2}{|c|}{ Ketahanan Aus } & \multirow{2}{*}{$\begin{array}{c}\text { Penyerapan } \\
\text { air rerata } \\
\text { maks. }(\%) \\
\end{array}$} \\
\hline & Rerata & Minimal & Rerata & Minimal & \\
\hline A & 40 & 35 & 0.090 & 0,103 & 3 \\
\hline$B$ & 20 & 17 & 0,130 & 0,149 & 6 \\
\hline $\mathrm{C}$ & 15 & 12,5 & 0,160 & 0,184 & 8 \\
\hline $\mathrm{D}$ & 10 & 8,5 & 0,219 & 0,251 & 10 \\
\hline
\end{tabular}

(Sumber: SNI-03-0691-1996)

Paving block dengan mutu A digunakan untuk jalan. Paving block mutu $B$ digunakan untuk pelataran parkir. Paving block mutu $C$ untuk pejalan kaki. Paving block mutu D digunakan untuk taman dan penggunaan lain.

\section{METOdologi PENELITIAN}

\subsection{Persiapan Material}

Mekanisme penelitian ii dapat dilihat pada Gambar 1. Botol jenis HDPE dikumpulkan dari gudang botot di jalan Sunggal, Medan. Setelah dikumpulkan, plastik dibersihkan dengan melakukan pencucian dengan sabun pembersih untuk memastikan tidak ada kotoran yang tertinggal. Pencucian juga dilakukan pada ijuk sebelum digunakan sebagai serat.

Serat ijuk yang digunakan pada penelitian ini ialah serat panjang $3 \mathrm{~cm}$; dan variasi persentase campuran $1 \%, 2 \%$ dan $3 \%$ dari volume paving block. Masing- 
masing variasi terdiri dari 5 buah sampel, sehingga total benda uji ialah 20 buah, atau seperti uraian pada Tabel 2.

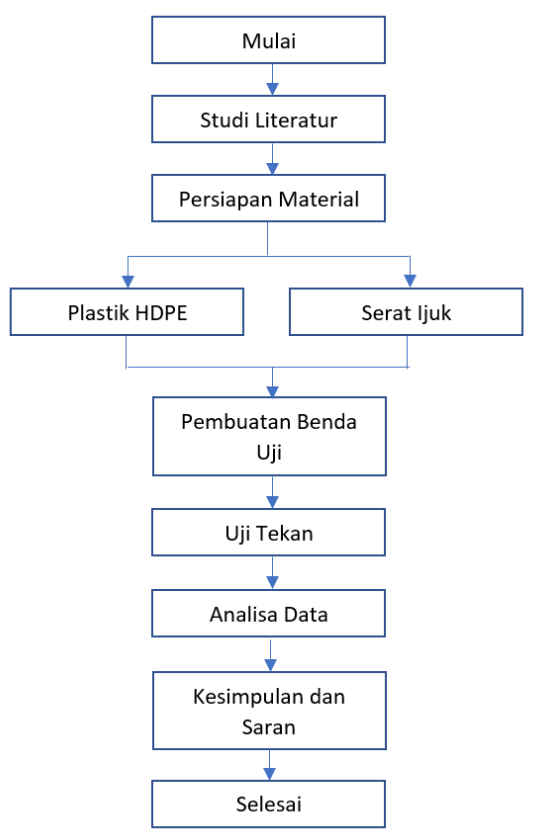

Gambar 1. Flow chart penelitian

Tabel 2. Jumlah Sampel Paving Block

\begin{tabular}{|c|c|c|c|}
\hline No. & $\begin{array}{c}\text { Persentase } \\
\text { campuran } \\
\text { serat }(\%)\end{array}$ & $\begin{array}{c}\text { Panjang } \\
\text { serat }(\mathrm{cm})\end{array}$ & $\begin{array}{c}\text { Jumlah sampel } \\
\text { (buah) }\end{array}$ \\
\hline 1 & 0 & 0 & 5 \\
\hline 2 & 1 & 1 & 5 \\
\hline 3 & 2 & 2 & 5 \\
\hline 4 & 3 & 1 & 5 \\
\hline \multicolumn{2}{|c|}{ Total sampel } & $\mathbf{2 0}$ \\
\hline
\end{tabular}

(Sumber: Data Penelitian)

Setelah serat ijuk dan limbah plastik selesai dibersihkan, prosedur dilanjutkan dengan pembakaran limbah plastik di kuali selama \pm 30 menit. Cetakan dilumasi dengan oli agar sampel tidak lengket. Setelah proses pembakaran sudah selesai, lelehan plastik dituangkan ke dalam cetakan. Serat ijuk ditaburkan sebanyak 2 kali, yaitu $2 \mathrm{~cm}$ dari serat bawah, lalu $2 \mathrm{~cm}$ dari serat atas. Penyebaran ijuk dilakukan secara acak dan cepat agar sampel tidak mengeras sebelum penuangan selesai. Prosedur dilanjutkan dengan memberikan tekanan pada sampe setelah memenuhi cetakan. Terakhir, sampel dikeluarkan dari cetakan setelah dibiarkan selama \pm 1 jam.

\subsection{Pengujian Sampel}

Pengujian yang dilakukan ialah dengan uji tekan, yaitu 24 jam setelah sampel dikeluarkan dari cetakan. Alat yang digunakan ialah compression testing machine dengan tahapan berikut:

a. Meletakkan sampel pada landasan

b. Mengatur jarum hingga menyentuh angka nol

c. Melakukan pembebanan tekan secara bertahap dan konstan

d. Mencatat nilai maksimum beban yang ditahan oleh sampel hingga mengalami patah.

Untuk mendapatkan kuat tekan dapat menggunakan rumus:

Kuat tekan $=\mathrm{P} / \mathrm{L}$

Dimana:

$\begin{array}{ll}\mathrm{P} & =\text { beban maksimum }(\mathrm{kg}) \\ \mathrm{L} & =\text { luas bidang tekan }\left(\mathrm{cm}^{2}\right)\end{array}$

\section{HASIL DAN PEMBAHASAN}

\subsection{Kuat tekan Paving Block Persentase} Campuran Serat Ijuk 0\%

Hasil uji pada kuat tekan paving block dengan bahan limbah plastik HDPE tanpa ada campuran serat ijuk dapat dilihat pada Tabel 3. Kuat tekan rata-rata yang dihasilkan yaitu 43,47 $\mathrm{kg} / \mathrm{cm}^{2}$. Kuat tekan maksimum yang dihasilkan yaitu $44,32 \mathrm{~kg} / \mathrm{cm}^{2}$. Nilai ini dibawah standar kuat tekan paving block.

Tabel 3. Kuat Tekan Paving Block dengan Kadar Serat Ijuk 0\%

\begin{tabular}{|c|c|c|}
\hline No. & Kadar Serat 0\% & Kuat Tekan $\left(\mathrm{kg} / \mathrm{cm}^{2}\right)$ \\
\hline 1 & Sampel 1 & 44,32 \\
\hline 2 & Sampel 2 & 42,61 \\
\hline 3 & Sampel 3 & 44,29 \\
\hline 4 & Sampel 4 & 43,85 \\
\hline 5 & Sampel 5 & 43,13 \\
\hline \multicolumn{2}{|c|}{ Rata-Rata } & $\mathbf{4 3 , 4 7}$ \\
\hline
\end{tabular}

(Sumber: Data Penelitian)

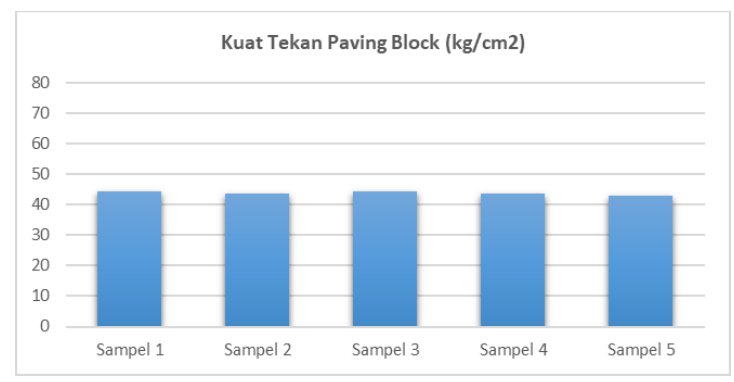

Gambar 2. Kuat Tekan Paving Block dengan Kadar Serat Ijuk 0\%

\subsection{Kuat tekan Paving Block Persentase Campuran Serat Ijuk 1\%}

Hasil uji kuat tekan paving block dngan persentase campuran serat ijuk $1 \%$, terjadi 
penurunan nilai. Kuat tekan maksimum yang dihasilkan yaitu sebesar $38,76 \mathrm{~kg} / \mathrm{cm}^{2}$, seperti yang terlihat pada Tabel 4 dibawah. Kuat tekan rata-rata yang dihasilkan yaitu sebesar 37,96 $\mathrm{kg} / \mathrm{cm}^{2}$. Nilai ini masih berada dibawah standar kuat tekan paving block.

Tabel 4. Kuat Tekan Paving Block dengan Kadar Serat Ijuk $1 \%$

\begin{tabular}{|c|c|c|}
\hline No. & Kadar Serat $1 \%$ & Kuat Tekan $\left(\mathrm{kg} / \mathrm{cm}^{2}\right)$ \\
\hline 1 & Sampel 1 & 38,76 \\
\hline 2 & Sampel 2 & 37,41 \\
\hline 3 & Sampel 3 & 38,17 \\
\hline 4 & Sampel 4 & 38,24 \\
\hline 5 & Sampel 5 & 37,21 \\
\hline \multicolumn{2}{|c|}{ Rata-Rata } & $\mathbf{3 7 , 9 6}$ \\
\hline
\end{tabular}

(Sumber: Data Penelitian)

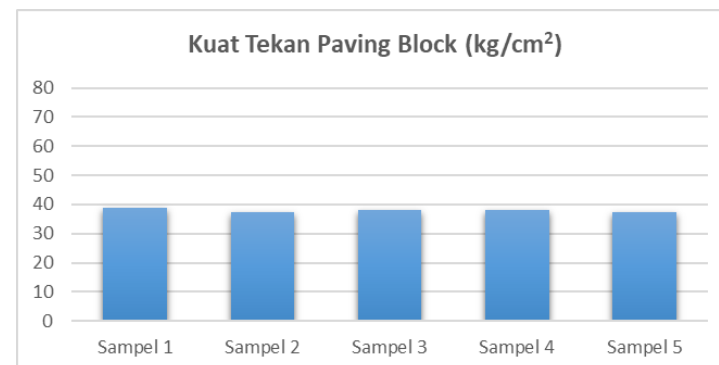

Gambar 3. Kuat Tekan Paving Block dengan Kadar Serat Ijuk 1\%

\subsection{Kuat tekan Paving Block Persentase} Campuran Serat Ijuk 2\%

Pengaruh penambahan campuran serat ijuk pada kuat tekan paving block dapat dilihat pada Tabel 5. Nilai rata-rata kuat tekan yaitu sebesar $45,28 \mathrm{~kg} / \mathrm{cm}^{2}$. Terjadi peingkatan kuat tekan jika dibandingkan paving block berbahan HDPE tanpa campuran serat ijuk. Namun, nilai ini masih dibawah standar SNI.

Tabel 5. Kuat Tekan Paving Block dengan Kadar Serat Ijuk 2\%

\begin{tabular}{|c|c|c|}
\hline No. & Kadar Serat 2\% & Kuat Tekan $\left(\mathrm{kg} / \mathrm{cm}^{2}\right)$ \\
\hline 1 & Sampel 1 & 45,37 \\
\hline 2 & Sampel 2 & 44,55 \\
\hline 3 & Sampel 3 & 44,84 \\
\hline 4 & Sampel 4 & 45,91 \\
\hline 5 & Sampel 5 & 45,74 \\
\hline \multicolumn{2}{|c|}{ Rata-Rata } & $\mathbf{4 5 , 2 8}$ \\
\hline
\end{tabular}

(Sumber: Data Penelitian)

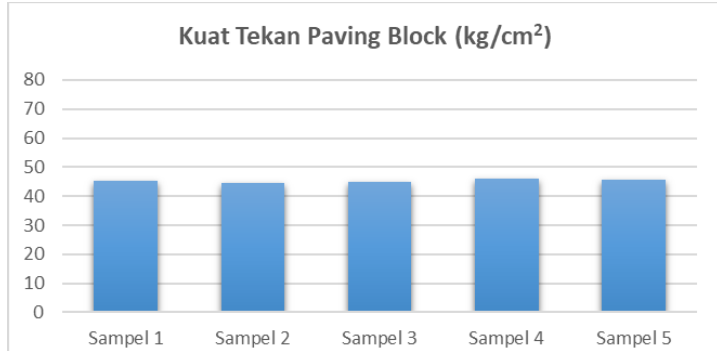

Gambar 4. Kuat Tekan Paving Block dengan Kadar Serat Ijuk 1\%

\subsection{Kuat tekan Paving Block Persentase Campuran Serat Ijuk 3\%}

Tabel 6 memperlihatkan kuat tekan paving block hasil dari penambahan campuran serat ijuk dengan persentase 3\%. Nilai rata-rata kuat tekan yang dihasilkan lebih rendah dibandingkan ketiga nilai kuat tekan rata-rata sebelumnya. Nilai kuat tekan rata-rata paving block hanya sebesar $36,32 \mathrm{~kg} / \mathrm{cm}^{2}$

Tabel 6. Kuat Tekan Paving Block dengan Kadar Serat Ijuk $2 \%$

\begin{tabular}{|c|c|c|}
\hline No. & Kadar Serat 3\% & Kuat Tekan $\left(\mathrm{kg} / \mathrm{cm}^{2}\right)$ \\
\hline 1 & Sampel 1 & 35,52 \\
\hline 2 & Sampel 2 & 36,15 \\
\hline 3 & Sampel 3 & 36,32 \\
\hline 4 & Sampel 4 & 36,26 \\
\hline 5 & Sampel 5 & 36,08 \\
\hline & Rata-Rata & $\mathbf{3 6 , 0 7}$ \\
\hline
\end{tabular}

(Sumber: Data Penelitian)

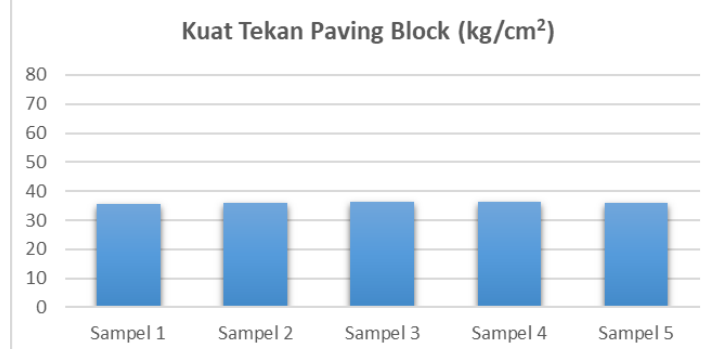

Gambar 5. Kuat Tekan Paving Block dengan Kadar Serat Ijuk 3\%

\subsection{Kuat Tekan Paving Block HDPE dengan Campuran Serat Ijuk dan Standar SNI}

Penggunaan serat ijuk pada paving block HDPE sempat mengalami tren peningkatan pada nilai kuat tekannya. Namun, kuat tekan tersebut tidak masuk kedalam nilai standar SNI. Secara umum, tren kuat tekan rata-rata paving block pada masing-masing persentase campuran serat ijuk dapat dilihat pada Gambar 6 . 


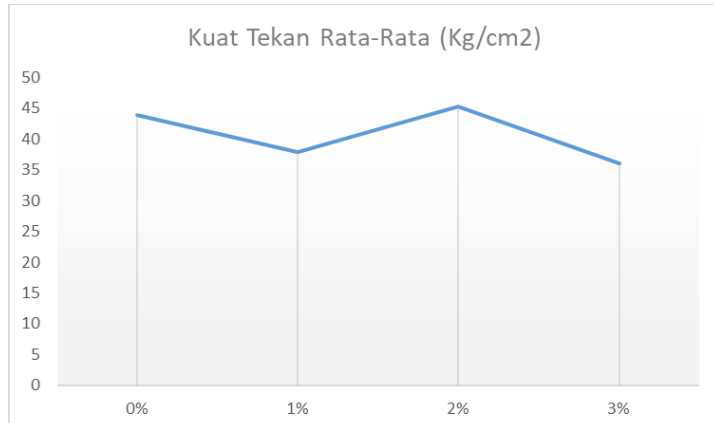

Gambar 5. Kuat Tekan Rata-Rata Paving Block pada Variasi Campuran Serat Ijuk

\section{KESIMPULAN DAN SARAN}

Berdasarkan uraian pada bab sebelumnya, didapatkan kesimpulan bahwa penggunaan serat ijuk sebagai campuran paving block HDPE tidak dapat memenuhi standar SNI. Kuat tekan maksimum yang dihasilkan yaitu pada persentase serat ijuk $2 \%$. Pada variasi tersebut, kuat tekan maksimum yang dihasilkan yaitu 45,91 $\mathrm{kg} / \mathrm{cm}^{2}$ dan kuat tekan rata-ratanya sebesar $45,28 \mathrm{~kg} / \mathrm{cm}^{2}$.

Perlu adanya penelitian lebih lanjut mengenai serat ijuk sebagai bagai bahan campuran paving block. Penelian saat ini menggunakan serat ijuk sepanjang $3 \mathrm{~cm}$. Untuk penelitian selanjutnya dapat dicoba dengan menggunakan variasi panjang serat yang lain. Selain itu, sebagai upaya untuk mengurangi limbah plastik, perlu adanya penelitian lebih lanjut terkait penggunaan limbah plastik untuk digunakan sebagai material lain seperti bahan konstruksi.

\section{DAFTAR PUSTAKA}

[1] Adibroto F., Pengaruh Penambahan Berbagai Jenis Serat pada Kuat Tekan Paving Block. Jurnal Rekayasa Sipil, vol.10, no. 1, pp. 1-11, 2014.

[2] Hutauruk, D.M.H, Pengaruh Serat Bendrat Terhadap Kuat Tekan Paving Block Berbahan Dasar Limbah Plastik HDPE, Journal of Civil Engineering, Building and Transportation, vol. , no. 1, pp. 10-16, 2021.

[3] Perdana, A.O., Wahyuni, A.S., Elhusna, Pengaruh Penambahan Serat Ijuk Terhadap Kuat Tarik Belah Beton dengan Faktor Air Semen 0,5, Jurnal Inersia, vol. 7, no. 2, pp. 7-12, 2015.

[4] Samlawi, A.K., Arifin, Y.F., Permana, P.Y. "Pembuatan dan Karakterisasi Material Komposit Serat Ijuk (Arenga Pinnata) Sebagai Bahan Baku Cover Body Sepeda Motor", Jurnal Info Teknik, 2017.
[5] Sari, K.I, Nusa, A.B., Pemanfaatan Limbah Plastik HDPE (High Density Polythylene) Sebagai Bahan Pembuatan Paving Block, Buletin Utama Teknik Vol. 15, No. 1, pp. 29-33, 2019.

[6] Surono, U.B., Sukoco, Analisa Sifat Fisis dan Mekanis Komposit Serat Ijuk dengan Bahan Matrik Poliester, Prosiding Seminar Nasional XI Rekayasa Teknologi Industri dan Informasi, pp.298-303, 2016. 